\title{
Duygusal Zekânın Kültürel Zekâ Üzerine Etkisinin Analizi: Kastamonu Üniversitesi Türk Dünyası Öğrencilerine Yönelik Bir Araştırma
}

\author{
Yavuz DEMIREL ${ }^{1}$, Erol TURAN ${ }^{2}$ ve Merve AKINCI ${ }^{3}$
}

\section{$\ddot{O} z$}

Duygusal zekâ, insanın duygularını kullanma yeteneği ve aynı zamanda başkalarının duygularını anlayıp, kendi duygularını ayarlama yeteneği olarak tanımlanır. Kültürel zekâ ise, farklı kültürel durumlara kendini uydurabilme yeteneğidir. Günümüz dünyasında artık çok kültürlü yaşam ortamları artmış, kültürel çeşitliliğin yaşandığı işler, meslekler, mekânlar çağın bir gereği olarak yaşam tarzı haline dönüşmüştür. Bu çerçevede kültürel zekâ, farklı kültürlerden insan gruplarını yönetebilmek, farklı ülkelerden ve kültürlerden gelen insanları anlamak ve farklı kültürlerle birlikte yaşayabilmek için geliştirilmesi zorunlu bir yetenek haline gelmiştir. Bu çalışma, çeşitli nedenlerle Kastamonu Üniversitesini tercih eden, Türk Dünyası Ülkelerinden gelen öğrenciler üzerinde gerçekleştirilmiştir. Araştırmada, duygusal zekâ ile kültürel zekâ arasındaki ilişki ortaya konularak duygusal zekânın kültürel zekâya olan etkisi belirlenmiştir. Duygusal ve kültürel zekânın ortak özelliği; geliştirilebilir, esnek ve çok fonksiyonlu dinamik bir yapıya sahip oluşudur. Yapılan çalışmada duygusal zekâ tek boyuta sahipken, kültürel zekâ; farkındalık, davranışsal ve biliş olmak üzere üç alt boyut şeklinde adlandırılmıştır. Yapılan analizler sonucunda, duygusal zekâ ile kültürel zekâ arasında pozitif yönlü kuvvetli bir ilişki saptanmış ve duygusal zekânın kültürel zekâyı olumlu yönde etkilediği belirlenmiştir.

Anabtar Kelimeler: Duygusal Zekâ, Kültürel Zekâ, Çok Kültürlü Eğitim, Türk Dünyası Öğrencileri

\section{Analysis of Effectiveness on Emotional Intelligence to Cultural Intelligence: A Research for the Turkish World Countries Students of Kastamonu University}

\begin{abstract}
Emotional intelligence is defined as the ability to use one's emotions and at the same time understand the feelings of others and the ability to adjust their own feelings. Cultural intelligence is the ability to adapt itself to different cultural situations. In today's world, multicultural living environments have increased, cultural diversity works, occupations and places have become a lifestyle as a necessity of the age. In this context, cultural intelligence has become a necessary skill to be developed to manage groups of people from different cultures, to understand people from different countries and cultures, and to live together with different cultures. This study has been carried out on Turkish World Countries students who preferred Kastamonu University for various reasons. In the study, the relationship between emotional intelligence and cultural intelligence was revealed and the effect of emotional intelligence on cultural intelligence was determined. The common feature of emotional and cultural intelligence is that they have flexible and multi-functional dynamic structure. While emotional intelligence has a single dimension, cultural intelligence has three sub-dimensions like awareness, behavioral and cognition. As a result of the analyses, a strong positive relationship was found between emotional intelligence and cultural intelligence, and it was determined that emotional intelligence positively affected cultural intelligence.
\end{abstract}

Key Words: Emotional Intelligence, Cultural Intelligence, Multi-Cultural Education, Students of Turkish World

\section{Atıf İçin / Please Cite As:}

Demirel, Y., Turan, E. ve Akınc1, M. (2020). Duygusal zekânın kültürel zekâ üzerine etkisinin analizi: Kastamonu üniversitesi Türk dünyası öğrencilerine yönelik bir araştırma. Manas Sosyal Araştırmalar Dergisi, 9(1), 222-234.

\footnotetext{
${ }^{1}$ Prof. Dr. - Kastamonu Üniversitesi İktisadi ve İdari Bilimler Fakültesi, ydemirel@kastamonu.edu.tr ORCID: 0000-0003-3478-6307

2 Doç. Dr. - Kastamonu Üniversitesi İktisadi ve İdari Bilimler Fakültesi, eturan@kastamonu.edu.tr ORCID: 0000-0003-0343-7622

3 Öğr. Gör. - Kastamonu Üniversitesi Kastamonu MYO, makinci@kastamonu.edu.tr - ORCID: 0000-0001-6529-9224
} 


\section{Giriş}

Küreselleşmenin pek çok boyutu olmasına rağmen en önemli boyutu, uluslararası kültürel farklılıkların azalmasına vurgu yapmasıdır. Kültürlerarası farklılıkların ortadan kalkmasıyla birlikte, ortak toplumsal ilişkilerin de dünya ölçeğinde giderek arttığı görülmektedir. Küreselleşme ile birlikte, kültürel kimlikler sürekli yeniden inşa edilir hale gelmiş ve bu süreç dünya ölçeğinde tüm kültürleri içine alarak gittikçe hızlanmışır (Özyurt, 2009, s. 34). Küreselleşme olgusu bir taraftan kültürler arası etkileşimi artırırken diğer taraftan da farklı kültürel özelliklere sahip insanların bir arada yaşamasını zorunlu kılmaktadır. Bu durum çok-kültürlülük kavramını doğurmuştur. Çok-kültürlülük, farklılıkların bir zenginlik olmasını sağlarken aynı zamanda çatışmaları önleyerek ortak bir yaşam kültürü oluşturmayı da sağlamaktadır. Bu hususta çok-kültürlülük, sosyal girişim olarak düşünülebilir (Yakışır, 2009, s. 2).

Küreselleşmenin yanı sıra iç savaşlar nedeni ile de ortaya çıkan olumsuz sosyal hareketlikler çeşitlilik sonucunu doğurmaktadır (Yaylac1, 2017, s. 345-364). 2000'li yıllarda uluslararasılaşma, üniversitelerin geleceğe yönelik stratejilerinin ayrılmaz bir parçası olarak yükseköğretimin asli görevi haline gelmiştir. Üniversiteler Arası Kurulun raporuna göre Uluslarasılaşmanın Türk yükseköğretimi için kaçınılmaz bir süreç olduğu vurgulanmaktadır (ÜAK, 2016, s. 6). Bu hususta kültür algısı ihtiyacı, refah üzerine atılmış bir zenginlik olarak ifade edilmektedir (Earley ve Ang, 2003, s. 31). Böylelikle kültürel çeşitliliğin yoğun yaşandığı ortamlarda, farklılıklara duyarlı olmak kaçınılmaz hale gelmektedir. Bilgi toplumuna geçişle birlikte, bilgi ve sermaye akışı ile orantılı olarak, kültürel bakımdan heterojen toplumlarda artış gözlenmiştir (İlbuğa, 2010, s. 163-180). Bishop vd. (2011) örgüt içinde paydaş profilindeki değişimlerin, ülkeler arasındaki çok yönlü öğrenci transferinin kaçınılmaz bir sonucu olarak ifade etmektedirler. Çok kültürlü eğitim, bireylerin kendilerini diğer kültürlerin gözünden görebilmelerini sağlamaktadır. Bu durum bireylere, kendilerini daha iyi tanıyabilmeleri ve farklı kültürlere sayg1 duyabilmeleri, farklı etnik gruplara nasıl davranması gerektĭgi bilgisini ve becerisini kazandırmaktadır (Banks, 2001, s. 123; Gezer ve Şahin, 2015, s. 173-188). Bu bakımdan çok-kültürlü ortamlarda toplumun yapı taşı niteliğinde olan kurumların da bu duyarlılığa sahip olması beklenmektedir. Bu noktada üniversiteler, kültürel heterojen ortamlar olarak nitelendirilebilmekte ve çok etnisiteli bir yapıyı teşkil etmektedir (İlbuğa, 2010, s. 163-180). Günümüz dünyasında kültürel farklılıkların öneminin artması, özellikle başka ülkelerden ve kültürlerden gelenlerin uyum zorlukları yaşaması, kültürel zekâ olgusunu uluslararası ilişkiler ve bireylerin uluslararası uyumları hususunda ön plana çıkarmıştır (Mercan, 2012, s. 4). Bu önemden yola çıkılarak, çok kültürlü ortamlardan olan üniversitelerdeki yabancı öğrencilerin kültürel zekâ düzeylerine duygusal zekâlarının etkisinin ortaya çıkarılması alanyazın bakımından da önemlidir.

Çalışmada alanyazın ışı̆̆ında, duygusal zekâ ile kültürel zekâ arasındaki ilişki ele alınarak duygusal zekânın kültürel zekâya olan etkisi tespit edilmeye çalışılmıştır. Bu bağlamda Kastamonu Üniversitesinde okuyan ve tamamı Türk Dünyası Ülkelerinden gelen öğrenciler üzerinde bir anket uygulaması yapılarak elde edilen veriler analiz edilmiştir.

\section{Zekâ, Kültürel Zekâ ve Boyutları}

İnsan zihnini çözmeye çalışan "zekâ" ile ilgili araştırmaların 1800’lü yıllara dayandığ dönemlerde zekâ kavramı daha basit, tekil ve gerçek yaşamdan soyutlandırılarak, ele alınmış bir kavram iken; zamanla yapılan çalışmalar sayesinde yeni boyutlar kazanmıştır. Gardner 1983 yılında, zekânın geliştirilebilir, esnek ve dinamik, çok fonksiyonlu bir yapı olduğunu çoklu zekâ kuramı ile ifade etmektedir. Böylelikle içerisine çevresel faktörler ve duygular da katılarak yeniden değerlendirilmiştir (Petrides, 2017, s. 4). İlk olarak bir çocuğun zekâ düzeyini analiz edebilecek bir ölçek geliştirmek istendiğinde Eğitimci Paris, Alfred Binet tarafindan IQ (Intelligence Quotient) testi ortaya atılmış, bu test sonrasında ise öğrencilerin düşük ya da yüksek zekâ bölümlerine göre sınıflandırıldığı üstün yetenekliler ve özel eğitim sınıfları oluşturulmuştur. Günümüzde halen kullanılmakta olan Scholastic Aptitude Test (SAT) bu uygulamaya örnek olarak verilebilir. Bu test öğrencinin üniversite eğitimi için gerekli nitelikleri taşıyıp taşımadığını gösteren bir belge sunan niteliktedir. Öğrencinin üniversite yönelimi için temel yeteneklerini ölçerek, matematik, dilbilgisi, okuduğunu kavrama ve kelime bilgisi durumlarını analiz etmektedir. Bu bağlamda zekâ; belirli bilgi formlarını tanıma, öğrenme, hafıza ve akıl kapasitesine imkân ve izin veren şemsiye bir terim olarak ifade edilmektedir (Mayer vd., 2008, s. 503-517). Günümüzde ise bu terim daha çok, eğitim ve psikoloji alanındaki gelişmeler ışı̆̆ında, bireylerin neler yapabildiğinden ziyade, neleri yapabileceği üzerinde yoğunlaşmıştır. $\mathrm{Bu}$ testlerin çocukların değerlendirilmesinde yeterli kıstas olamayacağı görüşü yaygınlaşarak, onların ayrıca potansiyel yeteneklerinin ortaya çıkarılması gerektiği üzerinde durulmuştur. 
Çoklu zekâ kuramı da bu doğrultuda, yeni eğitsel yöntemlerin düşünülmesi için ortaya atılmış ve bir sıçrama tahtası olarak ifade edilmektedir (Talu, 1999, s. 64-72).

Gardner (1983); dilsel, müzikal, mantıksal-matematiksel, mekânsal, bedensel kinestetik, içsel ve kişisel olarak sekiz zekâ sınıflandırmasında bulunmaktadır (Posner, 2003, s. 13). Sistemsel zekâya sahip olma, personel gelişimi eylemleri üzerinde pozitif duygu teorisi ve pozitif psikoloji alanında çalışmaların yanı sıra (Gardner, 1983) duygusal zekâ; (Mayer vd., 2008) sosyal zekâ kavramlarını geliştirmişlerdir (Goleman, 2006; Fredickson, 2004; Reasonand Bradbury, 2001).

Kültürel zekâ, kültürlerarasında etkili bir şekilde iletişim kurma yeteneğini içerir. Diğger zekâ kavramlarına dayandırılmakla birlikte nispeten yeni bir fikir olarak görülmektedir (Thomas ve Inkson, 2009, s. 75). Kültürel zekâ bilişsel zekâ gibi stabil değil; duygusal zekâ gibi geliştirilebilir düzeyde bir zekâ türüdür (Mercan, 2016, s. 3).

Şekil 1, kültürel zekâya sahip olabilen kişinin; insanoğlunun, üç özelliğini ayırabilmesi gerektiğini ifade etmektedir. Bunlar: Evrensel insan, kendine özgü olan kişisel insan ve o kültürde kökleşmiş olan insandır (Earley ve Ang, 2003, s. 54). Kültürel farklılıklara bağlı olarak, yaşamları neticesinde tek bir yere bağlı kalamayan, her iki tarafa da tam olarak ait hissedemedikleri bir yaşam sürmektedirler. Zihinsel süreçler sayesinde ise; farklı kültürlerde karmaşık problemleri çözebilme, problemleri keşfedebilme, değer bulan ürünler sunma gibi fonksiyonları gerçekleştirebilmektedirler (İlbuğa, 2010, s. 163-180).

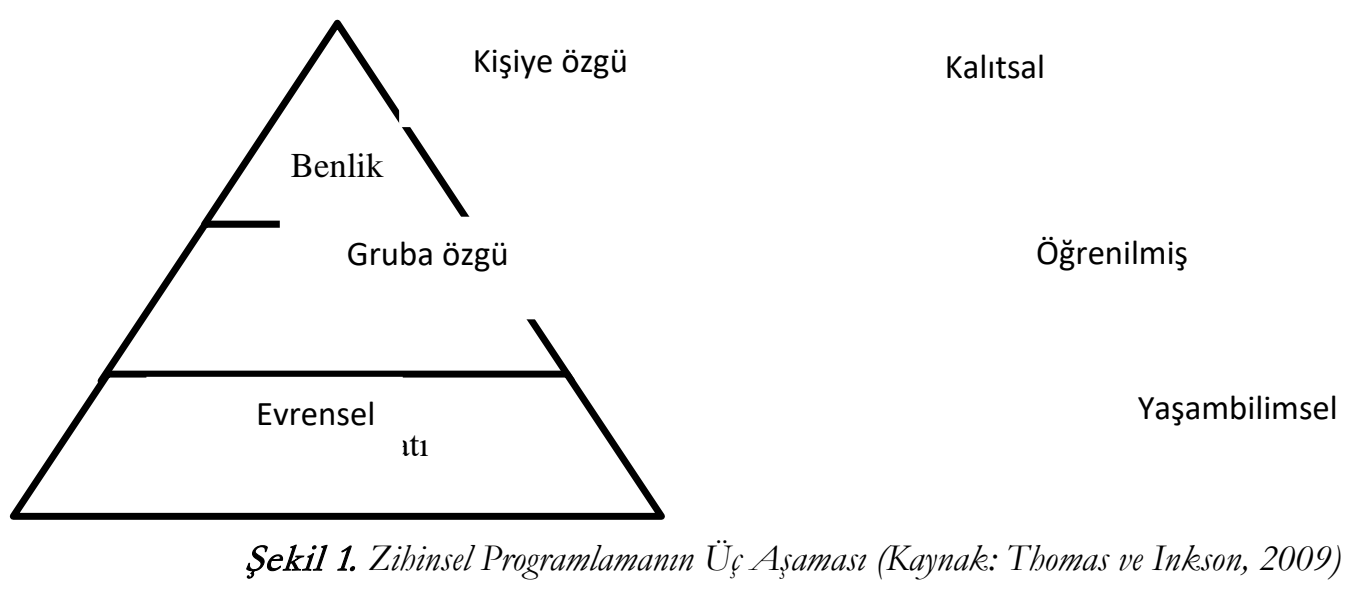

Şekil 2'de ele alınan kültürel iletişim süreci de bir iletişim süreci gibi, kanal aracllı̆ı ile kaynaktan hedef kitleye doğru aktarılmaktadır. Kültürel alanlar, kanallar aracılığı ile karşılaşmaktadır. Davranışlar, fikir, bilgi, duygu, tutum şeklinde kodlanarak alıcıya ses, hareket, model aracıllğı ile gönderilmektedir. Alıcı tarafından zihinsel programlama süzgecinden geçirilerek fikir, duygu, düşünce, beceri ve tutuma dönüşebilmektedir.

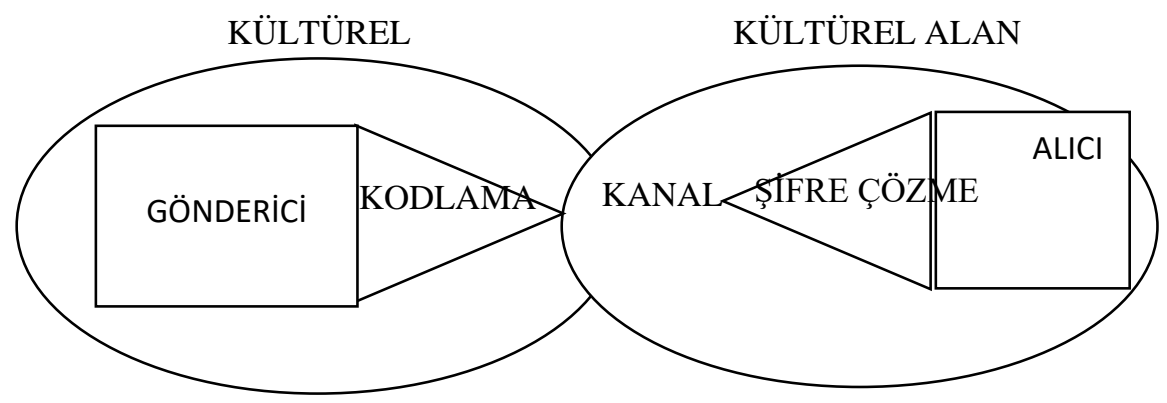

Şekil 2. Kültürel İletişim Süreci (Kaynak: Thomas, 2006)

Kültürel zekânın; kültürel uyum, sınır dışı performans, küresel liderlik, kültürlerarası müzakereler ve çok kültürlü takım süreçleri gibi çeşitli etkenlerin varllğı sayesinde, kültürler arası bağlamlarda, önemli sonuçları sergilediği bilinmektedir (Dyne ve Ang, 2012, s. 295-313). Kültürün değerler bağlamında farklı boyutları bulunmakla birlikte, ülke, şirket ve profesyonel kültür boyutlarının yanı sıra kültürü oluşturan 
temel unsurlar; dil, tutum, inanç ve değerler manevi boyutunu, estetik, eğitim, sosyal kurumlar, sosyal sistemler, gelişmişlik düzeyi ise maddi boyutunu ifade edilmektedir (Yeşil, 2009, s. 101-129).

Kültürel zekânın, 21. yüzyılda değişime ayak uydurma, verimlilik ve etkinlik için yönetici ve çalışanların kazanması gereken temel bir beceri olduğu ifade edilmektedir (Mercan, 2016, s. 3). Yeşil (2009) küresel örgütlerde kültürel zekâ konusunu kültürel farklılıkların yönetiminde alternatif bir stratejik kavram olarak ele almıştır. Kültürel zekâ kavramlaştırılırken, kültürel çeşitlilikle karakterize edilen durumların kültürel ipuçlarını uygun şekilde saptamas1, asimile etmesi, akıl yürütme ve hareket etme becerisi olarak tanımlanır (Earley ve Ang, 2003, s. 75). Bu nedenle farklı kültürden insanların, yaşanan olayları ve durumları farklı algılaması muhtemeldir. Dolayısıyla insanoğlu, herhangi bir zamanda, dünyanın sunmuş olduğu sürekli değişen uyarıcıların yalnızca bir kısmına katılabilmektedir. Böylelikle birey o yörenin yaşam stillerinden inanışına kadar, kendine hitap eden kültürel alg1 seçiminde bulunmaya gidecektir. Birey, toplum yapısına bağlı olarak, kültürel koşullanma yaparak, zamanla neleri öğrenmesi gerektiğini ve neleri görmezden geleceğini öğrenecektir (Thomas ve Inkson, 2009, s. 83).

Ülkeler arasında zorunlu ya da gönüllü olarak yaşanan yoğun göç hareketleri sebebiyle, kültürlerarası iletişim kurma gerekliliği sonucu doğmaktadır (Aksoy, 2016, s. 34-53). Kişinin öncelikle kendi kültürel değerlerine sahip olması ile birlikte misafir olduğu kültürün özelliklerini öğrenmesi ve yaşaması ile istemli bir değişimi meydana getirecektir. Kültürlerarası farklılıkları yönetmede kültürel zekâ kavramı da yapılan araştırmalarda genel kabul görmüştür. Bu doğrultuda kültürün en önemli özelliği Şekil 3’te ifade edilmiştir. Bu özellik; bilgi, farkındalık ve yeteneğin kesişimini oluşturan zihinsel programların paylaşılmasıdır (Uludağ ve Deveci, 2018, s. 70-76).

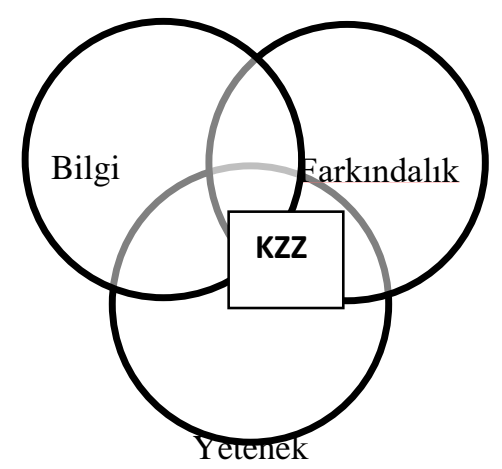

Şekil 3. KZ (Kültürel Zekâ Bileșenleri) (Kaynak: Thomas ve Inkson, 2009)

Zekâ çalışmalarının kökeni orijinallik, duyusal, antropemetrik ve hafıza fonksiyonlarında gözlenen bireysel farklılıklar üzerine kurulu geleneksel bir temele dayanmaktadır. Gardner, herhangi bir alandaki daha yüksek kabiliyete sahip olanların, diğer bireylerden daha farklı nöral mekanizmalara sahip olduklarını belirtmiştir. Bununla birlikte, genetikten performansa giden yol komplekstir ve nöral mekanizmalara bağlı değişiklik gösterebilmektedir. Posner ise; Gardner’in zekânın bireysel farklılık ölçümünü, nöropsikolojiye dayanan bir teoriye ittiğini vurgulamıştır. Bununla birlikte dikkat alanında yapılacak çalışmaların bilişsel psikolojinin tüm alanları için iyi olabileceğini vurgulamaktadır (Posner, 2003, s. 11). Bilişsel psikoloji, biliş ve bilişsel süreci incelemekte aynı zamanda, kişilerin davranışlarının anlaşılabilmesi için dış motivasyon yerine içten güdülenme üzerine yönelmektedir. Kişinin davranışlarını bireyin inanç, beklenti, amaç, tutum ve değerlerinin belirlediği ifade edilmektedir. Bilişsel süreç, bireylerin bilgiyi elde etme, saklama ve kullanma biçimlerinden meydana gelmektedir (Sarvan vd., 2003, s. 73-122). Bu davranışın gelişimi bir dizi alg1sal uyarlama, özel davranışsal beceriler, kişiler arası ilişkiler gibi genel beceri geliştirmeye bağlanmaktadır (Thomas ve Inkson, 2009, s. 87). Bu çerçevede kültürel zekanın bazı coğrafi ve kültürel farklılıkları anlamada önemli olduğu ifade edilebilir (Crowne, 2011, s. 48).

Aşağıda Şekil 4'te kültürel zekânın gelişim sürecinde zamanla tekrarlayıcı bir sürece gidilerek, S eğrisi çizildiği görülmektedir. Kültürel zekâya sahip olmak etkileşim veya interaktif öğrenme sürecini içermektedir. Yüksek kültürel zekâya sahip olmak için kültürel yetenekleri geliştirmek ve bu yetenekleri kullanmak büyük önem taşımaktadır. Kültürel yeteneklerin geliştirilmesi ise zaman bağlı olarak, kültürel etkileşime açık olmak ve kültürel değerleri öğrenme gayret ile mümkün olabilmektedir. Ayrrca kültürel zekânın geliştirilmesinde tecrübeye dayalı öğrenmenin etkin bir yöntem olabileceği belirtilmektedir. Farklı 
kültürlerde yaşamak, farklı kültürden insanlar ile etkileşim kurmak, bireyin hayatında yeni ilişkiler, zenginlikler ve olanaklara sahip olmasına zemin hazırlayacaktır (Mercan, 2016, s. 41).

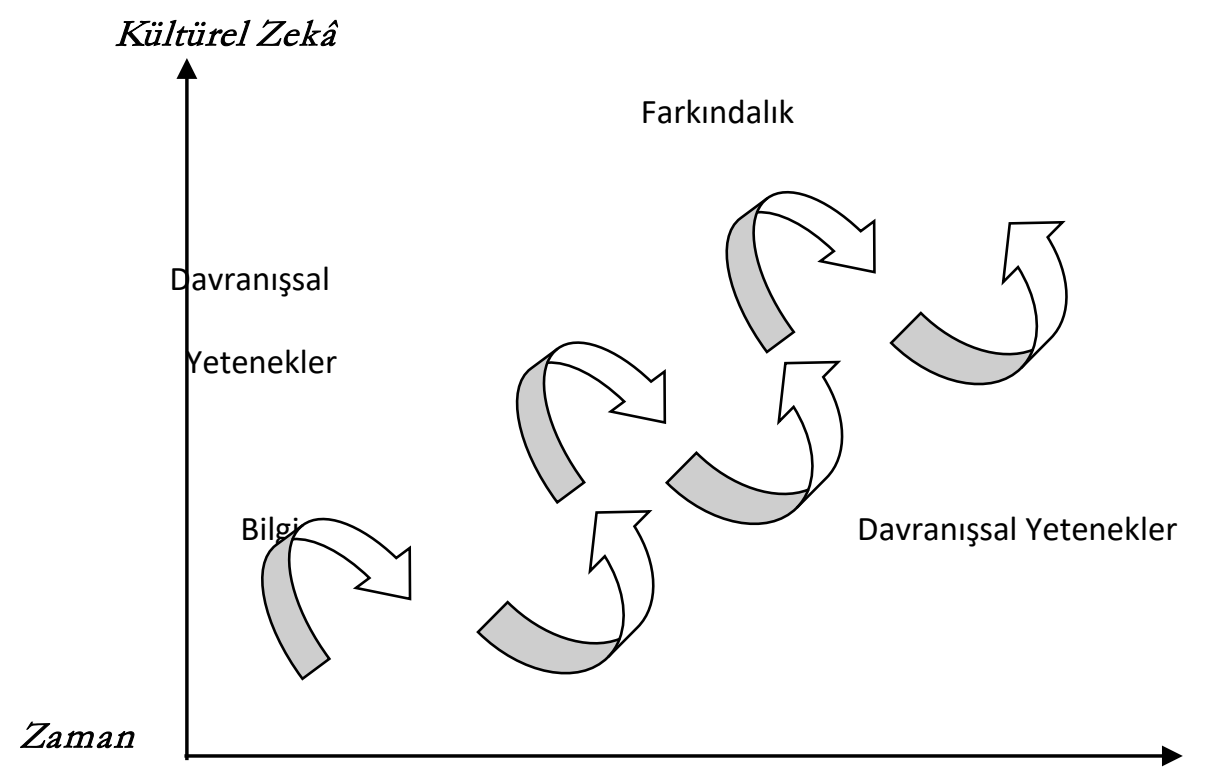

Sekil 4. Kültürel Zekânn Gelisimi (Kaynak: Thomas ve Inkson, 2009)

Farklı sembol formları beynin (cerebralcortex) farklı bölümlerine hizmet etmektedir. Biyolojik faktörlere ilaveten kültür de zekâ gelişiminde başat role sahiptir (Talu, 1999, s. 64-72). Yapılan çalışmalarda, kültürel zekânın alt boyutları; üstbilişsel, bilişsel, motivasyonel ve davranışsal zekâ faktörleri olarak boyutlandırılmıştır (Earley ve Ang, 2003, s. 27). Farklı çalışmalarda kültürel zekânın farklı boyutları ele alınmakla birlikte, bu boyutların birbiriyle örtüştügü genel kabul görmüş niteliktedir (Ersoy ve Ehtiyar, 2015, s. 42-60).

Bilişsel kültürel zekâ, kültürler ve kültürel farklılıklar hakkında genel bilgi ve bilgi yapılarını yansıtır. Üstbiliş ve biliş, bireyin bilişsel işlevini temsil eden zihinsel yeteneklerdir. Motivasyon ise başka bir zihinsel kabiliyettir. Bu süreç, sürücünün bilişsel süreçlerini ve seçimin bir başka önemli zekâ noktası olarak kabul eder (Dyne ve Ang, 2012, s. 295-313). Metabilişsel kültürel zekâ, kültürler arası etkileşimler sırasında, bireyin bilinçli kültürel farkındalık düzeyini ve yönetici işlemeyi ifade eder (Earley ve Ang, 2003, s. 32). Motivasyonel kültürel zekâ, enerjiyi, kültürlerarası durumlarda işleyişe ve gerçekleştirmeye doğru yönlendirmek ve sürdürmek için zihinsel kapasiteyi yansıtır. "Gerçek dünya" problem çözme içinkritik olan bilinçli bilişin motivasyonlu doğasını ele alır (Ceci, 1996, s. 103).

Bilişsel, metabilişsel ve motivasyonel zekânın (zihinsel işleyişi içeren) tersine, davranışsal zekâ, eski motor becerilerin davranışsal yeteneğini ifade eder ve bir dizi sözel ve sözel olmayan eylemleri içerir. Davranışsal kültürel zekâ alt boyutlanı aktive edildiğinde, kültürler arası ortamlarda davranışsallıklarını gösterirler. Bu durum kod değiştirme ve kültürel çevreye uyum sağlamayı gerektirir. Etkileyici kültürlerden gelenler, duygusal ifadeleri iyi bir davranış olarak gören tarafsız kültürlerden gelen insanlarla etkileşimde bulunurken daha az hareketli ve yüksek sesle davranışsal kültürel zekâlarını gösterir (Dyne ve Ang, 2012, s. 295-313).

\section{Duygusal Zekâ ve Boyutları}

İnsanın duygularını kullanma becerisi veya toplumdaki diğer üyelerin hislerini, düşüncelerini anlama ve bu anlayış neticesinde kendi hislerini ayarlama yeteneği olarak tanımlanan duygusal zekâ, kuşkusuz kültürel zekâ ile yakından ilişkilidir. Kültürel zekâ ise, insanın farklı kültürel durumlara kendini uyumlaştırma çabası veya yeteneğidir (Crowne, 2011, s. 45).

Bununla birlikte, duygusal zekâ, zekânın farklı boyutlarıyla ilgilenmekte ve kültürel zekâ ortamını aşacak şekilde duyguları anlamak ve yönetmek yeteneği olarak değerlendirilebilir (Mercan, 2016, s. 36). Genel zekâ yeteneği ise ağırlıklı olarak bilişsel yetenekler ile ilgilenirken, kültürel olarak farklı durumları ikincil planda değerlendirmektedir. Bu değerlendirmeye yönelik de zekânın davranışsal ve motivasyonel yönleri üzerinde durulması kaçınılmaz olmuştur (Dyne ve Ang, 2012, s. 295-313). Riggio ve Reichard (2008) duygusal becerileri; duygusal ifade, duygusal duyarlllik ve duygusal kontrol şeklinde ifade etmektedirler. Duygusal ifade gücü, iletişim sırasında tarafların iletişimin içeriğine göre duygusal tepkilerini 
ortaya koyabilme yeteneğiyken, duygusal duyarlılık, başkalarının sözel olmayan ya da duygusal ifadelerini alg1lama ve yorumlama becerisini ifade eder. Duygusal kontrolün ise, sözel olmayan ve duygusal göstergeleri düzenlemeyi ifade etmekte olduğunu vurgulamışlardır.

Böylelikle davranışsal eğitim, insanlara istedikleri davranışları yapma olanağı sunarken, istenmeyen davranışların yapılmasından da kaçınmayı sunmaktadır (Yeşil, 2009, s. 101-129). Davranış yönetmeye yönelik üç sosyal beceri tanımlanmıştır: Sosyal ifade, sosyal duyarlılık ve sosyal kontrol. Sosyal ifade, diğer bireylerle sosyal etkileşimde bulunma konusunda sözlü ve yetenekli iletişim kurabilme yeteneğidir. Sosyal duyarlılık, sözel dinleme becerisidir, aynı zamanda sosyal durumları "okuyabilme" ve sosyal kurallar ve normlar hakkında genel bilgi birikimidir. Sosyal kontrol ise, sosyal durumlara ilişkin, karmaşık sosyal rol oynama becerileri ve incelemesi anlamındadır (Riggio ve Reichard, 2008, s. 169-185).

Duygusal beceriler, duyguları doğru ifade etme, okuma ve anlama becerisiyle ilgilidir. Bunların hepsi duygusal zekâ bileşenlerini oluşturmaktadır. Bununla birlikte, duyguların zihinsel işlemeyi bildirme biçimlerini de içerir. Duygusal beceriler, duygusal zekânın daha "sosyal” unsurlarını temsil eder, çünkü sosyal etkileşimde bireyler arasında veya duyguların nasıl iletildiğine odaklanırlar. Yetenekler modeline göre duygusal zekâ ise, dört genel duygusal yetenekten oluşur (Riggio ve Reichard, 2008, s. 169-185):

1. Duyguları ifade etme yeteneğinin yanı sıra, kendini ve başkalarını duyguları tanıma yeteneğini içeren duyguları tanımlamak;

2. Düşünceyi kolaylaştırmak için duyguları kullanma, düşünme süreçlerini iyileştirmek için duyguları kullanma ve olumlu ruh hallerinin gücünü kullanma;

3. Duyguların karmaşıklıklarını ve inceliklerini ve karşılıklı ilişkileri de dâhil olmak üzere duyguları anlamak; ve

4. Duygusal duyguları düzenlemede ve kontrol etmede, olumlu bir şekilde duyguları yöneten duyguları yönetme.

Kültürel zekâ, bireyin karşıt kültür, alt kültür, toplumsal ve uluslararası kültürler ile etkileşim sonucu ortaya çıkmaktadır. Bu süreçte bireyin söz konusu kültürler hakkında edindiği bilgi ve birikimler kültürel zekânın temelini oluşturmaktadır. Özellikle kültürel zekâ düzeyi yüksek olan bireyler diğer kültürler hakkında hem bilgi sahibidirler hem de bu kültürlerin farkındadırlar. Dolayısıyla bu özelliklere sahip bireyler etkileşime girerken kültürel birikimlerini değerlendirirler. Maddi ve manevi kültürel bilgi birikimleri sayesinde çok hızlı bir etkileşim ve iletişim kurarlar (İlhan ve Çetin, 2014, s. 4-15). Bireylerin kültürel zekâya sahip olmalarında ise araştırma, inceleme, gözlem, öğrenme isteği, farkındalık, iletişim gibi hususlar etki olmaktadır. Bu bağlamda bireyler diğerleriyle etkileşimde bulunma becerileri bakımından farklılaşırlar. $\mathrm{Bu}$ durum farklılaşmaların somut bir örneği olarak ifade edilebilir. Aynı zamanda; din, duygusallık, kurallara uymama, informel ilişkiler, genel yaşam koşulları, oryantasyon süreci eğitimler ve bireysel hazırlıklar, dile duyulan ihtiyaç, iletişim zorlukları, motive eden unsurlar, kültürel görelilik konularında anlamlı derecede farklıliklar bulunmaktadır.

\section{Yöntem}

Çalışmanın amacı doğrultusunda, Kastamonu Üniversitesini tercih eden Türk Dünyası Ülkelerinden gelen öğrencilerin, kültürel zekâlanı ile duygusal zekâları arasındaki ilişkiyi ortaya koyarak, duygusal zekânın kültürel zekâ üzerine olan etkisini belirlemek için cevap aranacak sorular ve hipotezler Tablo 1'de verilmiştir.

Tablo 1. Calişmanin Hipotezleri

\begin{tabular}{ll}
\hline Araştırma Sorusu & Araştırmanın Hipotezleri \\
\hline $\begin{array}{l}\text { Duygusal zekâ ile kültürel zekâ düzeyi arasında bir ilişki } \\
\text { var mıdır? }\end{array}$ & $\begin{array}{l}\text { 1. } \mathbf{H}_{1} \text { : Duygusal zekâ ile kültürel zekâ arasında anlamlı bir } \\
\text { ilişki vardır. }\end{array}$ \\
Duygusal zekâ, kültürel zekâ düzeyini etkiler mi? & 2. $\mathbf{H}_{2}$ : Duygusal zekâ, kültürel zekâyı etkilemektedir. \\
\hline
\end{tabular}

Çalışma, Kastamonu Üniversitesinde eğitim gören, Türk Dünyası Ülkelerinden gelen öğrencileri kapsamaktadır. Çalışmanın sadece bir üniversitede ve Türk Dünyası Ülkelerinden gelen öğrenciler ile sınırlı kalması çalışmanın en önemli kısıtını oluşturmaktadır. Bu sınırlılı̆̆a rağmen çalışma sonuçlarının hangi üniversite bünyesinde olursa olsun öğrenci hareketliliğine önem veren üniversite öğrencileri ve çalışanlarına aynı zamanda tercihlerdeki tatmin derecesine bağlı olarak uluslararası ögrenci ofislerine de önemli faydalar sağlayacağı düşünülmektedir. 
Bu çalışmanın ana Türk Dünyası Ülkelerinden gelen ve öğrenim gören yaklaşık 1350 öğrenci oluşturmaktadır. Araştırma kapsamına Türkçe hazırlık programındaki öğrenciler dahil edilmemiştir. Kolayda örneklem yöntemine göre 264 öğrenciye anket uygulanarak veriler toplanmıştır. Örneklemin, ana kitlenin yaklaşık \%20'sini temsil ettiği görülmektedir. Verilerin toplanmasında, Wells (2017)'in çalışmasından Türkçe'ye uyarlanan 20 ifadeden oluşan kültürel zekâ ölçeği ve Suehs (2015)'in çalışmasından Türkçe'ye uyarlanan 16 maddelik duygusal zekâ ölçeği kullanılmıştır.

\section{Bulgular}

Araştırma bulguları SPSS 23.00 paket programı aracıllğıyla ortaya konulmuştur. Araştırma bulguları, örnekleme dahil edilen öğrencilere ilişkin sosyo-demografik özelliklerin ortaya konulması, ölçeklere ilişkin güvenirlik ve geçerlik analizi, korelasyon analizi ve regresyon analizi ile verilmiştir. Bu bağlamda öncelikle, öğrencilerin sosyo-demografik özelliklerine ilişkin dağılımlar, ölçeklerin yapı ve iç tutarlılıklarına ilişkin sonuçlar, kültürel zekâ ile duygusal zekâ arandaki ilişkiyi ortaya koyan korelasyon ve regresyon analizi sonuçlarına değinilmiştir.

\section{Örneklemin Sosyo-Demografik Özellikleri}

Anketi yanıtlayan toplam 264 katılımcının, \% 22,3’ü kadın, \% 77,7'si erkek; bunların \% 3’ü evli \% 97'si bekârdır. Katılımciların; \% 3'ü meslek yüksekokulu, \% 7,2'si yüksekokul, \% 89, 8’i fakültede yükseköğrenim görmektedir; \% 3,8’i 4.sınıf, \% 10, 6’sı 3. sınıf, \% 19, 3’ü 2.sınıf, \% 64'ü 1. sinıfta eğitim görmektedir. Yaş dağılımları, \% 49,2 21-25, \% 47,3 ile 16-20 ve \% 3,4’ü ise 26-30 yaş aralığında oldukları tespit edilmiştir. Katılımcların 87'sinin Azerbaycan, 57'sinin Kırgızistan, 51'nin Kazakistan, 32'sinin Türkmenistan, 27'sinin Özbekistan, 10'nunun da Doğu Türkistan'dan geldiği anlaşılmaktadır.

\section{Geçerlilik ve Güvenirlik Analizleri}

Çalısmada verilerin toplanmasında faydalanılan ölçeklerin güvenilirlik tespitinde Cronbach's Alpha katsayısı, geçerlilik tespitinde ise doğrulayıcı faktör analizi yapılmıştır. Duygusal zekâ ölçeğinin Cronbach's Alpha katsayısı 0,928 ve kültürel zekâ ölçeğinin Cronbach's Alpha katsayısı ise 0,924'tür. Doğrulayıc1 faktör analiz sonuçları ise Tablo 2 ve Tablo 3’te verilmiştir. Ölçek alfa katsayısının 0,92 olması ise yapılan testlerin \% 92 güvenilir olduğunu göstermektedir. Örneklemde duygusal zekâya ilişkin değerler tek faktör üzerinde toplanmış olup, bu faktör toplam varyansın \% 48,317'sini açıklamaktadır. Duygusal zekâya ilişkin değerlendirme soruları arasında anlamlı farklılık bulunmuştur $(\mathrm{p}<0,05)$.

Tablo 2. Duygusal Zekâ Ölçeğinin Güvenilirlik-Geçerlilik. Analizị

\begin{tabular}{lc}
\hline Duygusal Zekâ (Faktör ve Değişkenler) & Yük Değerleri \\
\hline Kendi duygularımı iyi bir şekilde anlarım. &, 768 \\
Ben her zaman en iyisini yapabilmek için kendi kendimi cesaretlendiririm. &, 750 \\
Ne hissettiğimi gerçekten anlarım. &, 744 \\
Kendim için hedefler belirler ve o hedeflere ulaşmak için elimden geleni yapmaya çalışırım. &, 727 \\
Ben kendi duygularımı kontrol etme konusunda oldukça yetenekliyim. &, 717 \\
Ben duygularımı iyi kontrol ederim. &, 716 \\
Başkalarının duygu ve hislerine karşı duyarlıyım &, 715 \\
Ben öfkemi kontrol edebilir ve zorlukların üstesinden gelebilirim. &, 710 \\
Çevremdeki insanların duygularını iyi anlarım. &, 708 \\
Çoğu zaman hissettiğim duygunun nedenini anlarım. &, 702 \\
Mutlu olup olmadığımı her zaman bilirim. &, 679 \\
Başkalarının duygularını gözlemleme noktasında iyi bir gözlemciyim. &, 671 \\
Arkadaşlarımın davranışlarından hangi duygu içerisinde olduklarını anlarım. &, 650 \\
Ben kendi kendime motive olan birisiyim. &, 647 \\
Ben her zaman çok öfkelendiğimde hızlı bir şekilde sakinleşebilirim. &, 595 \\
Ben her zaman kendimin, kendi kendine yeterli biri olduğunu söylerim. &, 595 \\
\hline Faktör Alfa Katsayısı &, 928 \\
Faktör Açılanan Varyans (\%) & 48,317 \\
Ölçek Alfa Katsayısı &, 928 \\
Ölceğe Illiskkin Açılanan Toplam Varyans (\%) & 48,317 \\
KMO Oranı \%) &, 940 \\
\hline
\end{tabular}

Gözlenen korelasyon katsayıları büyüklüğ̈ ile kısmi korelasyon katsayılarını karşılayan bir değer olan Kaiser-Meyer-Olkin örneklem yeterliliği ölçütü olarak bilinmektedir. KMO (Kaiser-Meyer-OlkinMeasure of SamplingAdequacy) oranın yüksek olması veri setinin faktör analizine uygun olduğunu göstermektedir (Kalayc1, 2017, s. 322). Duygusal zekâ boyutunda KMO değerine bakıldığında 0,940 olduğu görülmüştür. Ölçeğin bütününe ilişkin kültürel zekâ örneklem yeterlilik değeri 0,932 olarak analiz edilmiştir. 
Kültürel zekâ alt boyutlarının KMO değerleri ise sırasıyla: 0,$893 ; 0,747$ ve 0,806 şeklinde sonuçlanmıştır. Bu sonuçlara göre belirtilen faktörlerin yeterli ve uygun olduğu gözlenmiştir. Ayrıca tüm faktörlere uygulanan güvenilirlik testinde ise; 0,924 sonuçla mükemmel derecede güvenilir olduğu belirlenmiştir.

Tablo 3. Kültürel Zekầ Ölçeğinin Güvenilirlik-Geçerlilik. Analiz̧i

\begin{tabular}{|c|c|c|c|}
\hline \multirow[t]{2}{*}{ Kültürel Zekâ (Faktörler ve Değişkenler) } & \multicolumn{2}{|c|}{ Yük Değerleri } & \multirow[b]{2}{*}{3} \\
\hline & 1 & 2 & \\
\hline \multicolumn{4}{|l|}{ Faktör 1: Farkındalık } \\
\hline Yabancı bir/birkaç dilin (kelime, gramer vb.) kurallarını biliyorum. &, 779 & & \\
\hline $\begin{array}{l}\text { Tanımadığım bir kültürün içindeki yerel insanlar ile sosyalleşebileceğime dair kendime } \\
\text { güveniyorum. }\end{array}$ & 773 & & \\
\hline Farklı kültürlerden insanlarla etkileșim içine girmekten hoşlanırım. &, 750 & & \\
\hline $\begin{array}{l}\text { Farklı kültürlerden gelen insanlarla etkileşim kurarken kültürel bilgimin doğruluğunu } \\
\text { zihnimde kontrol ederim. }\end{array}$ &, 714 & & \\
\hline $\begin{array}{l}\text { Farklı bir kültür içindeki alışveriş biçimlerine alışabileceğim konusunda kendime } \\
\text { güveniyorum. }\end{array}$ & , 690 & & \\
\hline $\begin{array}{l}\text { Farklı kültürlerden insanlarla etkileşim içindeyken kullandığım kültürel bilginin farkında } \\
\text { olurum. }\end{array}$ & , 685 & & \\
\hline $\begin{array}{l}\text { Yeni veya tanımadım bir kültürün üyesi insanlarla etkileşim içindeyken kültürel bilgimi } \\
\text { ayarlarım. }\end{array}$ & , 621 & & \\
\hline $\begin{array}{l}\text { Farklı bir kültürün üyesi insanlarla etkileşim kurarken kültürel bilgimi nasıl uyguladığımın } \\
\text { farkındayım. }\end{array}$ & , 605 & & \\
\hline $\begin{array}{l}\text { Bana tümüyle yeni olan bir kültüre uyum sağlama sırasında oluşabilecek stres durumlarıyla } \\
\text { baş edebileceğime eminim. }\end{array}$ &, 513 & & \\
\hline Tanımadığım kültürler içinde yaşamak hoșuma gider. &, 471 & & \\
\hline \multicolumn{4}{|l|}{ Faktör 2: Davranışsal } \\
\hline Kültürlerarası bir etkileşim sırasında gerekirse yüz ifademi değiştiririm. & &, 718 & \\
\hline $\begin{array}{l}\text { Kültürlerarası bir etkileşim sırasında gerekirse sözlü olmayan davranışlarımı (el, baş } \\
\text { hareketleri vb.) değiştiririm. }\end{array}$ & &, 665 & \\
\hline Kültürlerarası bir etkileșim sırasında gerekirse konușmamın sıklığını değiștiririm. & &, 518 & \\
\hline $\begin{array}{l}\text { Farklı kültürlerarası durumlara uyum sağlamak için duraklama ve sessizliği farklı olarak } \\
\text { kullanırım. }\end{array}$ & & 479 & \\
\hline $\begin{array}{l}\text { Kültürlerarası bir etkileşim sırasında gerekirse sözlü davranışlarımı (aksan, ses tonu vb.) } \\
\text { değiştiririm. }\end{array}$ & &, 414 & \\
\hline \multicolumn{4}{|l|}{ Faktör 3: Bilişsel } \\
\hline Başka kültürlerin yasal ve ekonomik sistemleri hakkında bilgi sahibiyim. & & &, 723 \\
\hline Bașka kültürlerin sanat ve zanaatı hakkında bilgi sahibiyim. & & & 686 \\
\hline Başka kültürlerin değerleri ve dini inançları hakkında bilgi sahibiyim. & & &, 621 \\
\hline Başka kültürlerin evlilik sistemleri hakkında bilgi sahibiyim. & & &, 549 \\
\hline Bașka kültürlerin sözlü olmayan davranıs kuralları hakkında bilgi sahibiyim. & & &, 520 \\
\hline Faktörlere Iliskin Alfa Katsayısı &, 893 &, 747 & 806 \\
\hline Her Bir Faktör Tarafindan Açılanan Varyans (\%) & 24,61 & 14,98 & 14,009 \\
\hline Ölçĕ̌in Alfa Katsayisı & &, 924 & \\
\hline Ölcek İiskin Aciklanan Toplam Varyans (\%) & & 53,60 & \\
\hline KMO Orani $(\%)$ & &, 932 & \\
\hline
\end{tabular}

Faktör sayısını belirlemede değişik yöntemler söz konusu olmakla birlikte, örneklemimizde özdeğer istatistiği (Eigenvalue) 1'den büyük olan faktörler anlamlı olarak belirtilmiştir (Kalayc1, 2017, s. 328). Tablo 3’te bu şekilde 3 faktör söz konusudur. Birinci faktör toplam varyansın \% 24,616'sını açıklamaktadır. 1. ve 2. faktörler toplam varyansın \% 39,597'sini açılamaktadır. Üç faktör ise toplam varyansın \% 53,606'sını açıklamaktadır.

\section{Duygusal Zekâ ile Kültürel Zekâ Arasındaki İlişki}

Duygusal zekâ ile kültürel zekâ boyutları arasındaki ilişkiyi belirlemek için korelasyon analizi yapılmış ve Tablo 4'te verilmiştir. 


\begin{tabular}{lccc}
\hline Faktörler & Ortalama & Standart Sapma & N \\
\hline Faktör 1: Farkındalık & 3,3572 &, 90698 & 264 \\
Faktör 2: Davranışsal & 3,2356 &, 85198 & 264 \\
Faktör 3: Bilişs & 3,2273 &, 93671 & 264 \\
Faktör 1: Duygusal Zekâ & 3,4894 &, 85662 & 264 \\
\hline
\end{tabular}

Not: Ortalama ve standart sapma değgerleri; 1) Kesinlikle katılmyorum, ............. 5) Kesinlikle katıliyorum ölçeği baz. alınarak hesaplanmıştır.

Tablo 4, modele dâhil edilen değişkenlerin aritmetik ortalamasını ve standart sapmalarını göstermektedir. Verilen cevaplara göre, sapmaların en fazla olduğu faktör üçüncü faktör olarak gözlenmektedir. 264 öğrencinin katılımıyla gerçekleştirilen hesaplamalar dikkate alınarak, verilen cevaplar doğrultusunda, ortalamaların kararsızlık boyutunu aştı̆̆ı, katılıyor ifadelerine yaklaştığı söylenebilir.

Kültürel zekâ alt boyutları ile duygusal zekâ arasındaki ilişkiyi tespit etmek amacıyla korelasyon analizi yapılmış olup sonuçlar Tablo 5'de yer almaktadır.

Tablo 5. Duygusal Zekâ ile Kültürel Zekânm Boyutlan Arasındaki İlişki

\begin{tabular}{lccccc}
\hline Kültürel Zekânın Alt Boyutları ve Duygusal Zekâ & & $\mathbf{1}$ & $\mathbf{2}$ & $\mathbf{3}$ & $\mathbf{4}$ \\
\hline 1) Farkındalık & $\mathrm{r}$ & 1 & & & \\
2) Davranışsal & $\mathrm{p}$ & & & & \\
& $\mathrm{r}$ &, $654^{* *}$ & 1 & & \\
3) Bilişsel & $\mathrm{p}$ &, 001 & & & \\
& $\mathrm{r}$ &, $717^{* *}$ &, $568^{* *}$ & 1 & \\
4) Duygusal Zekâ & $\mathrm{p}$ &, 001 &, 001 & & \\
\end{tabular}

**. Korelâsyon ilişkisi $\mathrm{p}<0,05$ düzeyinde anlamlıdır. N:264

Tablo 5 incelendiğinde, faktörler arasında istatistiksel olarak pozitif yönlü anlamlı bir ilişki olduğu görülmektedir. Duygusal zekâ ile kültürel zekânın alt boyutu farkındalık alt boyutu arasındaki ilisski 0,756, davranışsal alt boyutu arasındaki ilişki ,571 ve biliş boyutu arasındaki ilişki ise ,617 olarak belirlenmiştir. Sonuçlara göre duygusal zekâ ile kültürel zekânın alt boyutları arasında yüksek düzeyde pozitif bir ilişkinin olduğu dikkat çekmektedir. Öğrencilerin sahip oldukları duygusal zekâ düzeyleri yükseldikçe sahip oldukları kültürel zekâ düzeyleri de artmaktadır. Bu durum araştırmanın " $\mathrm{H}_{1}$ : Duygusal zekâ ile kültürel zekâ arasında anlamlı bir ilişki vardır" hipotezini doğrulamaktadır.

\section{Duygusal Zekânın Kültürel Zekâya Etkisi}

Duygusal zekânın kültürel zekâ üzerine olan etkisini belirlemek için regresyon analizi yapılmış ve sonuçlar Tablo 6'da verilmiştir. Duygusal zekâ bağımsız değişken olarak, kültürel zekâ ve boyutları ise bağımlı değişken olarak ele alınmıştır.

Tablo 6. Duygusal Zekânnn Kültürel Zekâya Etkisi

\begin{tabular}{lrrrrrr}
\hline Kültürel Zekâ ve Boyutları & Beta (B) & t-değeri & \multicolumn{1}{c}{ p } & \multicolumn{1}{c}{ F } & \multicolumn{1}{c}{ p } & \multicolumn{1}{c}{$\mathbf{R}^{\mathbf{2}}$} \\
\hline Farkındalık &, 756 & 18,68 &, 001 & 346,15 &, 001 &, 57 \\
Davranışsal &, 572 & 11,25 &, 001 & 126,70 &, 001 &, 32 \\
Bilişsel &, 616 & 12,63 &, 001 & 159,51 &, 001 &, 37 \\
Genel Olarak Kültürel Zekâ & $\mathbf{, 7 4 2}$ & $\mathbf{1 7 , 8 6}$ & $\mathbf{, 0 0 1}$ & $\mathbf{3 1 9 , 2 0}$ & $\mathbf{0 0 1}$ & $\mathbf{, 5 5}$ \\
\hline
\end{tabular}

Modelin gözlemlenen değerine göre regresyon modeline ne kadar uyumlu olduğu regresyon modelindeki F değerlerine göre yorumlanır (Gürbüz ve Şahin, 2016, s. 274-275). Tablodaki anlamlllk değeri (p) 0.05 değerinden küçük bir değere sahip olduğundan model istatistiksel olarak anlamlı bulunmuştur. Düzeltilmiş $\mathrm{R}^{2}$ değerine göre örneklem grubunda duygusal zekâ, modele dâhil edilen kültürel zekâ değişkenin genel olarak \%55'ni açıklanmaktadır. Geriye kalan \%45'lik kısmı ise modele dâhil etmediğimiz değişkenler tarafından açıklanır. Modelde öncelikle duygusal zekânın kültürel zekânın her bir alt boyutuna etkisi daha sonra ise duygusal zekânın genel olarak kültürel zekâ üzerine olan etkisi saptanmışıı. Özellikle duygusal zekânın, farkındalık algısını daha çok etkilediği anlaşılmaktadır. Diğer bir ifadeyle Duygusal zekâ düzeyindeki pozitif bir birimlik artış, öğrencilerin farkındalık düzeyinde. 756'lık bir artışı sağlamaktadır. Bu bağlamda "H $\mathbf{H}_{2}$ : Duygusal zekâ, kültürel zekâyı etkilemektedir." hipotezi de kabul edilmiştir.

\section{Tartışma, Sonuç ve Öneriler}


Bu araştırmada; Kastamonu Üniversitesinde okuyan Türk Dünyası Ülkelerinden gelen öğrencilerin duygusal zekâ̂ düzeyleri ile kültürel zekâ düzeyleri arasındaki ilişkinin incelenmesi amaçlanmıştır. $\mathrm{Bu}$ amaçla; öncelikle değişkenler arasındaki ilişkiler test edilmiş, elde edilen bulgular öğrencilerin duygusal zekẫ alt boyutları ile kültürel zekâ düzeyleri arasında pozitif ve anlamlı ilişkiler olduğunu göstermiştir. Bu bulguya göre; duygusal zekẫ düzeyi arttıkça öğrencilerin kültürel zekâ düzeylerinde yükselme olmaktadır.

Zekâ sınıflandırmaları ile ilgili konular literatürde oldukça geniş bir yere sahiptir. Sahip olunan duygusal zekâ düzeyine bağlı olarak kültürel zekâ kavramı etkileyen niteliktedir. Kültürel zekâ kavramları kişilerin iş yaşamını, üniversite tercihlerini ve performansını şekillendirebilir potansiyele sahiptir. Kültürel zekâ kavramı bireylerin tercihlerini etkilemesi ve performans düzeylerini arttırması gerekirken, bilgi, farkındalık ve davranışsal yeteneklerin zamanla gelişmesi ile kültürel zekâ kavramı da gelişebilmektedir. Öğrenme ve farkındalık eğrisi sayesinde sahip olunan duygusal zekâ düzeyinin etkisine bağlı olarak, kültür alg1sı etkilenmektedir. Beklenen tutumlar; ortama ilişkin özellikler, toplumun kökeni ve eğitim programları sayesinde, psikolojik uyum ve adaptasyon gibi istenen tutumlara dönüşmektedir. Kültürel etkileşimler nezdinde olumsuz tutumlar ise kültürel şok ile sonuçlanabilmektedir.

Bu çalışmada yapılan anket çalış̧masının analizi sonucunda deneklerin kültürel zekâ düzeylerinde cinsiyet, yaş vb. boyutlarda farklılıklar tespit edilmiş ve duygusal zekânın kültürel zekâya karşı düzeltici bir etkiye sahip olduğu sonucuna varılmıştır. Bizim bulduğumuz sonuçlara paralel biçimde Uludağ ve Deveci (2018), yine üniversite öğrencileri üzerinde yaptıkları araştırmada, kültürel zekâ düzeyinde farklılaşmalar ortaya koymuşlardır. Bu çalışmalarında katılımcıların büyük çoğunluğunu kadınlar ile erkeklerin kültürel zekâ düzeyleri göreli olarak farklılaşmaktadır. Mercan (2016), turizm sektöründe yaptığı çalısmada ise, kadın ve erkeklerin aritmetik ortalamalarının arasındaki fark istatistiksel olarak anlamlı çıkmamıştır. Yaş değişkenine göre kültürel zekânın alt boyutu olan bilişsel-davranışsal zekâ düzeylerinde anlamlı farklılık bulunmakla birlikte kültürel zekâ seviyesinin en yoğun yaşandığ1 yaş grubu 26-30 yaş arası olarak gözlemlemişlerdir. Bu konu çerçevesinde Hindistan'da yapılan bir çalışmada, toplumların kültürel farklılıklara maruz kalma düzeyi ve toplumdan topluma değişebilen sosyal, kültürel ve duygusal zekâ anlayışının ne olduğuna dair düşüncel yaklaşımlarda bulunulmuştur. Böylelikle insan kaynakları süreci olarak değer algılarına dikkat çekilmiştir (Crowne, 2011, s. 47). Kültürel zekânın etkisinin tespit edilmesinde ise farkındalık, davranışsal ve biliş düzeyi üç boyutta ayrı ayrı değerlendirilmiştir. Duygusal zekâ ise tek boyut olarak analize tabi tutulmuştur.

Araştırmanın temel amacı çerçevesinde; duygusal zekâ düzeyinin yordayıcılık gücünün belirlenmesi için yapılan aşamalı regresyon analizi sonuçları ise; yukardaki bulguyu destekleyecek şekilde duygusal zekâ düzeyinin öğrencilerin kültürel zekâ düzeyleri üzerinde anlamlı bir yordayıcılık gücünün olduğunu göstermektedir (Tablo 6). Araştırmadan elde edilen bulgu, bu öğrencilerin duygusal zekâ alt boyutlarının farkındahk, davranısssal ve biliş- tamamının güçlü bir etkiye sahip olduğunu göstermektedir.

Bu konu üzerine yapilan çalışmalarda da benzer sonuçlar görülmektedir. Küreselleşme sürecinde liderlerin kültürel zekâ düzeyleri ile duygusal zeka düzeyleri arasında pozitif yönlü anlamlı bir ilişkinin (r: 62) olduğu tespit edilmiştir (Rockstuh, 2011, s. 832). Tanu ve Sandeep (2018) tarafindan Hindistan'da hizmet sektörü yöneticilerine yönelik yaptıklanı çalışmada yöneticilerin duygusal zekâ alg1lamaları ile kültürel zekâ alg1 düzeyleri arasında orta düzeyde pozitif bir ilişki $(r=, 53)$ olduğu ve kültürel zekâ düzeyi yüksek yöneticilerin değişime daha hızlı uyum sağladıkları belirlenmiştir. Amerika'da bir üniversitede 485 kattlımcı üzerine gerçekleştirilen bir çalışmada kültürel baskının kültürel zekâyı etkilediği ancak duygusal zekay1 etkilemediği görülmüştür (Crowne, 2013, s. 5). Alon ve Higgins (2005) ise küresel liderlik başarısında duygusal ve kültürel zekânın rolünün önemli olduğunu ve kültürel zekânın duygusal zekâyı olumlu yönde etkilediğini ortaya koymaktadır. Analiz sonuçları dikkate alındığında geliştirilebilir ve değişebilir nitelikte olan duygusal zekâ düzeyi kültür algısını şekillendirerek, bireylerin ülke/üniversite seçimlerine yönelik tutumlarında etken olduğu ileri sürülebilir. Bu seçimlerin, kişisel deneyimlerin yanı sıra sosyo-politik ilişkiler, kültür yapısı gibi faktörlerden etkilendiği de ileri sürülebilir. Bu bağlamda bu ülkelerden Türkiye'ye sistematik öğrenci hareketliliğinin, bu doğrultuda gelişimsel bir süreç olacağ1 kaçınılmazdır. Esasında sahip olunan kültürel değerler, bu ülkelerden öğrencilerin Türkiye'yi tercihlerini etkileyecektir. Bu tercih söz konusu bu ülkelerden Türkiye’ye doğru öğrenci hareketliliğini etkileyerek bu ülkelerle olan kültürel zenginliğe zemin hazırlayacaktır.

Araştırma kapsamına bir üniversitenin dâhil edilmiş olması ve diğer üniversitelerin dâhil edilmemiş olması çalışmanın yaygın etkisini azaltmaktadır. Bu nedenle gelecekte yapılacak çalışmalarda örnekleminin 
tüm kamu-özel-üniversitelerini kapsayacak şekilde genişletilmesi önem arz etmektedir. Bu sebeple çalışmanın sonuçlarını genişleterek yorumlamak, çalışma sonuçlarına göre genellemeler yapmak yanlış anlamlara yol açabilir

\section{Kaynakça}

Aksoy, Z. (2016).Kültürlerarası iletişim eğitiminde öğrencilerin kültürlerarası duyarlllık gelişimi öz değerlendirmeleri üzerine bir inceleme. Selcuk İletisim, 9(3), 34-53

Alon, I. ve Higgins, J. M. (2005).Global leadership success through emotional and cultural intelligences. Business Horizons, 48(6), 501-512.

Banks, J. A. (2001). Diversity within unity: essential principles for teacbing and learning in a multicultural society. Washington: University of Washington, Center for Multicultural Education.

Bishop, T., Reinke, J. ve Adams, T. (2011). Globalization: trends and perspectives. Journal of International Business Research, 10(1), 117-130.

Ceci, S. J. (1996). On intelligence: a bioecological treatise on intellectual development. Cambridge, MA: Harvard University Press.

Cogan, J. J. ve Morris, P. (2001).The development of civics values: an overview. International Journal of Educational Research, 35, 1 - 9.

Crowne, K. (2011).Explornng intelligences, organizational skills and leadership in Mumbai, India. International Journal of Business, Humanitie sand Technology, 1(2), 44-51.

Crowne, K. A. (2013). Cultural exposure, emotional intelligence, and cultural intelligence: an exploratory study. International Journal of Cross Cultural Management, 13(1), 5-22.

Deardoff, D. K. (2006). Identification and assessment of intercultural competence as a student outcome of internalization. Journal of Studies in International Education, 10(3), 254-272.

Dyne, V. L. ve Ang, S. (2012). Subdimensions of the four-factor model of cultural intelligence: Expanding the conceptualization and measurement of cultural intelligence. Social and Personality Compass, 6(4), 295-313.

Earley, P. C. ve S. Ang (2003). Cultural intelligence: individual interactions across cultures. Palo Alto, CA: Stanford University Press.

Ersoy, A. ve Ehtiyar, R. (2015).Kültürel farklılıkların yönetiminde kültürel zekânın rolü: Türk ve yabancı yöneticiler üzerine bir araştırma. Anatolia: Turižm Araştırmalar Dergisi, 26(1), 42- 60.

Fredrickson, B. L. (2004). The broaden-and-build theory of positive emotions. Philos TR Soc B: Biol Sci, 359, 13671377.

Gardner, H. (1983). Frames of mind: the theory of multiple intelligences. New York: Basic Books.

Gezer, M. ve Şahin,İ. F. (2015). Çokkültürlü eğitime yönelik tutum ve kültürel zekâ arasındaki ilişkinin yem ile incelenmesi. Doğu Coğrafya Dergisi, 38, 173-188.

Goleman, D. (2006). Social intelligence: the new science of social relationships. London: Hutchinson.

İlbuğa, E. (2010). Çokkültürlülük, ulusötesilik ve kültürlerarası iletişim yeterliği. Cankaya University Journal of Humanities and Social Sciences, 7(1), 163-180.

İlhan, M. ve Çetin, B. (2014).Sosyal ve kültürel zekâ arasındaki ilişkinin yapısal eşitlik modeli ile incelenmesi. Turkish Journal of Education, 3(2), 4-15.

Macnab, B. R. ve Worthley, R. (2012). Individual characteristics as predictors of cultural intelligence development: the relevance of self-efficacy. International Journal of Intercultural Relations, 36(1), 62-71.

Mayer, J. D., Salovey, P. ve Caruso, D. R. (2008). Emotional intelligence: New ability or eclectic traits? Am Psychol, 63, 503-517.

Mercan, N. (2016).Çok kültürlü ortamlarda kültürel zekânın kültürler arası duyarllık ilişkisine yönelik bir araştırma. Niğde Üniversitesi İktisadi ve İdari Bilimler Fakültesi Dergisi, 9(1), 1-13.

Özyurt, C. (2009). Toplumu yeniden düşünmek: kozmopolitanizm ve çokkültürlülük.VI. Ulusal Sosyoloji Kongresi: Toplumsal Dönissiimler ve Sosyolojik Yaklassimlar, Aydın: Adnan Menderes Üniversitesi.

Petrides, K. V. (2017). Intelligence, Emotional. (İcinde: J. P. Stein), Reference Module in Neuroscience and Biobehavioral Psychology, London: Elsevier.

Posner, M. I. (2003). Neural systems and individual differences. A commentary on frames of mind: the theory of multiple intelligences Annual Meeting of the American Educational Research Association in Chicago, IL, April.

Reason, P. ve Bradbury, H. (eds). (2001). Handbook of action researcb: participative inquiry and practice. London: Sage Publications.

Riggio, R. E. ve Reichard,R. J. (2008). The emotional and social intelligences of effective leadership: an emotional and social skill approach. Journal of Managerial Psychology, 23(2), 169-185.

Rockstuhl, T., Seiler, S., Ang, S., Van Dyne, L. ve Annen, H. (2011). Beyond general intelligence (IQ) and emotional intelligence (EQ): The role of cultural intelligence (CQ) on cross-border leadership effectiveness in a globalized world. Journal of Social Issues, 67(4), 825-840.

Sarvan, F., Arıcı, D., Özen, E. J., Özdemir, B. ve Tarcan İçigen, E. (2003). On stratejik yönetim okulu: Biçimleşme okulunun bütünleştirici çerçevesi. Akdeniz Üniversitesi İktisadi ve İdari Bilimler Fakëiltesi Dergisi, 6, 73-122.

Suehs, D. J. (2015). Emotional intelligence and employee engagement: a quantitative study to explore the relationship between the emotional intelligence of frontline managers and supervisors and the degree of employee 
engagement of their direct reports in a tertiary care health care setting, (İçinde: Ralph C. Wilson, Jr.), School of Education, London: St. John Fisher College.

Talu, N. (1999). Çoklu zekâ kuramı ve eğitime yansımaları. Hacettepe Üniversitesi Ë̆itim Fakültesi Dergisi, 5, 64-72.

Tanu, S. ve Sandeep, S. (2018). Relationship of emotional intelligence with cultural intelligence and change readiness of Indian managers in the service sector. Journal of Organizational Change Management, 4, 32-47.

Thomas, D. C. (2006). Domain and development of cultural intelligence: the importance of mindfulness. Groupand Organization Management, 31(1), 78-99.

Thomas, D. C. ve Inkson, K. (2009). Cultural intelligence: living and working globally, San Francisco, California: BerrettKoehler Publishers.

Uludağ, E. ve Deveci, G. (2018). Hemşirelik öğrencilerinin kültürel zekâlarının değerlendirilmesi. Gümüşhane Üniversitesi Să̆hk Bilimleri Dergisi, 3, 70-76.

ÜAK(2016). Türkiye'de yükseköğretim ve uluslararasılaşma. Analiz Dergisi, 1-32.

Yakışır, A. N. (2009). Modern bir olgu olarak çokkültürlülük (Yüksek Lisans Tezi). Selçuk Üniversitesi, Konya.

Yaylac1, G. F. (2017).Süper-çeşitlilik çağında çokkültürcülük. Hitit Üniversitesi, Sosyal Bilimler Enstitüsü Dergisi, 10, 345 364.

Yeşil, S. (2009). Kültürel farklillkların yönetimi ve alternatif bir strateji: kültürel zekâ. Kabramanmaraş Sütçü Imam Üniversitesi İktisadi ve İdari Bilimler Fakültesi Dergisi, (16), 101-129.

Wells, C. M. (2017). An analysis of global corporate culture and the relationship between cultural intelligence and transformational leadership. Nashville, Tennessee: Trevecca Nazarene University.

\section{EXTENDED ABSTRACT}

Globalization emphasizes the reduction of international cultural differences. This means that social relations are increasing their visibility on a world scale. At the same time globalization emphasizes that cultural identities can be reconstructed continuously. Thanks to the phenomenon of globalization, the world is shrinking, but different cultures and identities merge into multiculturalism to live together. Multiculturalism is considered an attempt to be an alternative to avoid conflict. Multiculturalism has been proposed as an alternative initiative.

These processes are known to make different societies more dependent on each other. The main factors affecting are the globalization of the economy, the globalization of scientific and technological civilizations, and the emergence of the information society. In the 2000s, internationalization has become an essential element and an inevitable tendency of higher education as an integral part of universities' future strategies. Internationalization is an inevitable process manic Turkey argued for higher education. In this respect, the need for cultural perception is expressed as richness on welfare. Thus, it becomes inevitable to be sensitive to differences in environments where cultural diversity is intense. In this respect, it is expected that the institutions which are the building blocks of the society in multicultural environments will have this sensitivity. At this point, universities can be characterized as cultural heterogeneous environments and constitute a multi-ethnic structure at this point.

In the context of these explanations, the relationship between emotional intelligence and cultural intelligence was determined and the effect of emotional intelligence on cultural intelligence was tried to be determined. The data were obtained from the Central Asian Republics students of Kastamonu University and analyzed.

The cause of these students studying in higher education in Turkey are as follows; providing facilities such as visa procedures, residence permit, strong economic-political links between countries, low level of education in their own country, opportunities to provide higher education, libertarian structure of higher education, cultural proximity, low living costs, economic development, geographical location, migration reasons such as facilities have come to the forefront. In this context, as a determinant of international migration preferences, it can be said that factors such as curricula, personal experiences as well as socio-political relations and cultural structure are effective.

The increasing importance of cultural differences, the difficulties of adaptation from foreigners, the role of cultural intelligence is taking part in the international management literature. Based on this importance, it is also essential in terms of literature to reveal the effect of emotional intelligence on foreign students' cultural intelligence levels in universities of multicultural environments. The main aim of study is to investigate the effect of emotional intelligence on cultural intelligence by revealing the relationship between the cultural intelligence and emotional intelligence of the students from Central Asian countries who prefer Kastamonu University. 
The number of questionnaires is limited to 264 and the data collection techniques are excluded from the survey. In spite of these constraints, it is thought that the results of the research will provide important clues to the international student offices on the basis of the degree of satisfaction of the university students and employees, who also place emphasis on student mobility, regardless of the university.

The universities, which are open to innovation and operate with innovative practices, are decisive for this study. For this reason, judicial sampling method was preferred among innovative universities in accordance with the quantitative research method in the field where it operates and based on the sampling, research data were collected from participants consisting of international students by means of a questionnaire.

Analysis of the research data was used SPSS 23.00 package program. The research data were given by the socio-demographic characteristics of the students included in the sample, reliability and validity analysis, correlation analysis and regression analysis.

The KMO value of emotional intelligence was 0,940 . The cultural intelligence of the whole scale was analyzed as 0,932 . KMO values of cultural intelligence sub-dimensions are as follows: 0,$893 ; 0,747$ and 0,806 . According to these results, it was observed that the stated factors were adequate and appropriate. In addition, the reliability test applied to all factors; it was found to be perfectly reliable with 0,924 results.

There was a strong relationship between emotional intelligence and cultural intelligence. At this point, it does not want strong correlations between the independent variables. The fact that the correlations between independent variables and 0,80 do not correlate the independent variables' contribution to the model and the power of the model.

There was a statistically significant difference between the factors and the relationship was $99 \%$ confidence level. The relationship between emotional intelligence and awareness of cultural intelligence has a strong relationship with 0,756 . There is also a strong relationship between the sub-dimensions of Awareness and Cognition in cultural intelligence. A moderate-strong relationship has emerged between the Awareness and Behavioral sub-dimensions of cultural intelligence with 0,654. Other correlation relationships between emotional intelligence and cultural intelligence sub-dimensions also have moderate relations.

In the determination of the effect of cultural intelligence, awareness, behavioral and cognitive levels were evaluated separately in three dimensions. Emotional intelligence was analyzed in one dimension. In the analysis, a statistically significant relationship was found between emotional intelligence and cultural intelligence.

When the results of the study are taken into consideration, the level of emotional intelligence, which can be changed and changed, will be shaped by the perception of culture, and it will be effective in individuals' attitudes towards university choices. Depending on the level of satisfaction experienced, the culture perception will be affected positively.

The fact that only one university based on the research and the existence of various constraints in the research has caused the research sample not to be extended to include all public-private-universities. For this reason, interpreting the results of the study and generalizing according to the results of the study can lead to misunderstandings. In the future, the scope of the studies to be carried out in this area can be broadened and different perspectives can be brought to the subject. Thus, it is advisable to conduct the research in a larger university. 